\title{
Effects of Humidity During Formation of Zinc Oxide Electron Contact Layers from a Diethylzinc Precursor Solution
}

\author{
Scott A. Mauger ${ }^{a}$, K. Xerxes Steirer ${ }^{b}$, Jonas Boéa,c,d, David P. Ostrowskic ${ }^{c}$ Dana C. Olson ${ }^{\mathrm{a}}$, Scott R. Hammond ${ }^{\mathrm{e}, *}$ \\ ${ }^{a}$ Chemistry and Nanoscience Center, National Renewable Energy Laboratory, Golden, CO, USA \\ ${ }^{b}$ Materials Science Center, National Renewable Energy Laboratory, Golden, CO, USA \\ ${ }^{c}$ Department of Electrical Engineering, University of Colorado, Boulder, CO, USA \\ ${ }^{d}$ Friedrich-Alexander University, Erlangen, Germany \\ ${ }^{e}$ SolarWindow Technologies, Inc., Columbia, MD, USA
}

\begin{abstract}
This work focuses on the role of humidity in the formation of $\mathrm{ZnO}$ thin films from a reactive diethylzinc precursor solution for use as the electron contact layer (ECL) in organic photovoltaic (OPV) devices. This method is well suited for flexible devices because the films are annealed at $120^{\circ} \mathrm{C}$, making the process compatible with polymer substrates. $\mathrm{ZnO}$ films were prepared by spin coating and annealing at different relative humidity (RH) levels. It is found that RH during coating and annealing affects the chemical and physical properties of the $\mathrm{ZnO}$ films. Using X-ray photoelectron spectroscopy it is found that increasing RH during the formation steps produces a more stoichiometric oxide and a higher $\mathrm{Zn} / \mathrm{O}$ ratio. Spectroscopic ellipsometry data shows a small decrease in the optical band gap with increased humidity, consistent with a more stoichiometric oxide. Kelvin probe measurements show that increased RH during formation results in a larger work function (i.e. further from vacuum). Consistent with these data, but counter to what might be expected, when these $\mathrm{ZnO}$ films are used as ECLs in OPV devices those with $\mathrm{ZnO}$ ECLs processed in low RH (less stoichiometric) had higher power conversion efficiency than those with high- $\mathrm{RH}$ processed $\mathrm{ZnO}$ due to improved open-circuit voltage. The increase in open-circuit voltage with decreasing humidity was observed with two different donor polymers and fullerene acceptors, which shows the trend is due to changes in $\mathrm{ZnO}$. The observed changes in open-circuit voltage follow the same trend as the $\mathrm{ZnO}$ work function indicating that the increase in open-circuit voltage with decreasing humidity is the result of improved energetics at the interface between the bulk-heterojunction and the $\mathrm{ZnO}$ layer due to a vacuum level shift.
\end{abstract}

Keywords: Organic Photovoltaics, Zinc Oxide, Processing, Humidity, Contact Layer

\section{Introduction}

Organic photovoltaics (OPV) remains a technology of interest due to its unique attributes such as solution processability, flexibility, and multiple discrete absorption bands. Solution processability allows for OPV modules to be fabricated using high-throughput rollto-roll coating methods such as slot-die coating and gravure printing. Based on recent estimates, modules produced using slot-coating with $5 \%$ power conversion efficiency (PCE) and a 3-5 year lifetime will have a comparable levelized cost of electricity (LCOE) to a coal power plant.[1] Lab-scale devices have achieved PCE's above $10 \%$, with submodules reaching $6.8 \%$ at an area of almost $400 \mathrm{~cm}^{2}$.[2] Additionally, fully-printed modules have recently been shown to maintain $95 \%$ of their initial efficiency after one year in outdoor testing experiments.[3] These results show that a module

\footnotetext{
* Corresponding Author

Email address: scotte solarwindow. com (Scott R. Hammond)

meeting the efficiency and lifetime requirements for grid parity may soon be attainable. Discrete absorption bands allow the color of a OPV module to be tuned for light management or aesthetics - an important consideration for building integrated applications.

For optimal stability, OPV devices are fabricated in an inverted architecture (also known as superstrate configuration) because they use more stable metal electrodes than conventional architecture devices. $[4,5]$ The inverted architecture requires a transparent, n-type material for the electron contact layer (ECL). Transparent oxides have been extensively used as carrier-selective contacts in OPV, with $\mathrm{ZnO}$ and $\mathrm{TiO}_{x}$ commonly used as the ECL.[6, 7] $\mathrm{ZnO}$ thin films can be formed from nanoparticle, sol-gel, or reactive precursor solutions.[8, 9, 10] Here, $\mathrm{ZnO}$ thin films formed from a reactive precursor solution of stabilized diethylzinc (DEZn) are studied to understand the effect of relative humidity during film formation. This DEZn method was initially developed for $\mathrm{ZnO}$-polymer hybrid solar cells, 
but has since been applied to $\mathrm{ZnO}$ thin films for OPV devices.[10, 5] It is well suited for roll-to-roll processing because it requires annealing at only $110^{\circ} \mathrm{C}$, which is at or below the glass transition temperature $\left(T_{g}\right)$ of polymer films such as polyethylene terephthalate (PET), polyethylene naphthalate (PEN) and polyimide. In contrast, a sol-gel route using zinc acetate $(\mathrm{ZnAc})$ usually requires annealing up to $300{ }^{\circ} \mathrm{C}$, which is well above $T_{g}$ for many polymer films $[9,11]$, although reports indicate it is possible to fabricate efficient OPV devices with $\mathrm{ZnAc}$-based $\mathrm{ZnO}$ annealed at only 100$110^{\circ} \mathrm{C} .[12,13]$

On its own, pyrophoric DEZn is too reactive to be useful for film formation from solution, so it is diluted and stabilized with toluene and tetrahydrofuran (THF). Once stabilized, DEZn can be processed in air via standard solution-processing techniques, such as spin coating. The conversion of DEZn to $\mathrm{ZnO}$ occurs in a two step process. For chemical vapor deposition (CVD) of $\mathrm{ZnO}$ from DEZn, molecular orbital studies have shown two reaction pathways..[14] The first reaction pathway is initiated by single hydrolysis

$\mathrm{Zn}\left(\mathrm{CH}_{2} \mathrm{CH}_{3}\right)_{2}+\mathrm{H}_{2} \mathrm{O} \longrightarrow \mathrm{Zn}\left(\mathrm{CH}_{2} \mathrm{CH}_{3}\right) \mathrm{OH}+\mathrm{C}_{2} \mathrm{H}_{6}$,

which is followed by the elimination of ethane

$$
\mathrm{Zn}\left(\mathrm{CH}_{2} \mathrm{CH}_{3}\right) \mathrm{OH} \longrightarrow \mathrm{ZnO}+\mathrm{C}_{2} \mathrm{H}_{6}
$$

to form $\mathrm{ZnO}$. The alternative pathway is initiated by double hydrolysis

$$
\mathrm{Zn}\left(\mathrm{CH}_{2} \mathrm{CH}_{3}\right)_{2}+2 \mathrm{H}_{2} \mathrm{O} \longrightarrow \mathrm{Zn}(\mathrm{OH})_{2}+2 \mathrm{C}_{2} \mathrm{H}_{6}
$$

and $\mathrm{ZnO}$ is formed by the elimination of water

$$
\mathrm{Zn}(\mathrm{OH})_{2} \longrightarrow \mathrm{ZnO}+\mathrm{H}_{2} \mathrm{O} \text {. }
$$

A study of the reaction in ether showed single hydrolysis (Eqn. 1) is the dominant reaction mechanism.[15] However, in all of the reaction conditions studied the $\mathrm{H}_{2} \mathrm{O}$ :DEZn ratio was never greater than $1: 1$, so this may have excluded double hydrolysis as pathway since it would need a ratio of 2:1. Hydrolysis is exothermic, where as elimination is endothermic, thus thermal annealing is necessary to convert the intermediate hydroxide to $\mathrm{ZnO}$. Since hydrolysis of DEZn is initiated by water, it likely that relative humidity $(\mathrm{RH})$ during coating and annealing will impact the formation of $\mathrm{ZnO}$. This was found to be the case in hybrid ZnO:MDMO-PPV (poly[2-methoxy-5-(3',7'dimethyloctyloxy)-1,4-phenylenevinylene]) solar cells, where the most efficient devices were made when the hybrid bulk heterojunction (BHJ) was spin coated and annealed in a nitrogen environment with 45-60 \% RH.[16] For these devices the objective was to form $\mathrm{ZnO}$ within the polymer matrix to create an intimately mixed network for efficient free-carrier generation. However, for
ZnO ECLs in polymer:fullerene OPV devices the objective is to create a dense, smooth layer with high optical transparency, thus the optimal humidity conditions may be different than for hybrid structures. A previous study on the solution formation of $\mathrm{ZnO}$ from $\mathrm{DEZn}$ showed that higher annealing temperature and humidity produces higher field-effect mobilities.[17]

There are also previous reports quantifying the role of processing conditions on the chemical composition of $\mathrm{ZnO}$ formed from DEZn through solution and atomic layer deposition (ALD). In ALD-grown films it was found that increasing temperature during formation resulted in a higher $\mathrm{Zn}: \mathrm{O}$ ratio and more stoichiometric oxide.[18] Solution processing results showed that $\mathrm{ZnO}$ films formed from DEZn are less stoichiometric than films formed from $\mathrm{ZnAc}$ and it was suggested that the fast decomposition of DEZn could be the cause.[11] Although, the effects of humidity and annealing temperature on the properties of $\mathrm{ZnO}$ films formed from DEZn has been previously studied,[17] this report focuses on the role of relative humidity during the formation of $\mathrm{ZnO}$ from a DEZn precursor solution. A wide range of humidity, from $10-75 \% \mathrm{RH}$, was explored during spin coating and annealing. The results show that relative humidity impacts the chemical composition of the $\mathrm{ZnO}$ film. Contrary to what was shown for hybrid devices and the previous study of OPV devices, polymer:fullerene OPV devices are found to be most efficient when the $\mathrm{ZnO}$ layer is formed in low humidity. In OPV devices with multiple donor:acceptor BHJ systems, the highest PCE is achieved when the $\mathrm{ZnO}$ layer is spin coated in low $\mathrm{RH}(10-15 \% \mathrm{RH})$ and annealed in a dry nitrogen glovebox. The improvements in PCE are primarily due to increases in the open-circuit voltage $\left(V_{o c}\right)$. These improvements are attributed to observed changes in work function that result from changes in chemical composition.

\section{Materials and Methods}

All substrates were cleaned in ultrasonic baths of acetone and deionized water for $30 \mathrm{~min}$ followed by rinsing with deionized water and drying with compressed $\mathrm{N}_{2}$. For ellipsometry, the substrates were single-side polished Si wafers with $100 \mathrm{~nm}$ of thermal oxide. For Kelvin probe and x-ray photoelectron spectroscopy, the substrates were unpatterned indium tin oxide (ITO) coated glass $(15 \Omega / \square)$. For OPV devices, the substrates were patterned ITO $(15 \Omega / \square)$ on glass. Humidity was measured using a VWR Traceable Temperature and $\mathrm{Hu}-$ midity Meter.

The precursor DEZn solution was made by mixing one part of a stock solution of diethylzinc (15 wt\%) in toluene (Sigma Aldrich, 220809) with three parts of uninhibited tetrahydrofuran (THF, Sigma Aldrich, 401757) in a glove box. The diethylzinc/toluene mixture was injected into the THF using a syringe and nee- 
dle to minimize exposure of DEZn to water. The films were deposited by spin coating. To control the humidity during spin coating a large piece of expanded polystyrene was used to cover the spin coater. Three holes were made in the cover to accommodate the gas line, humidity meter, and micropipet for solution dispensing. For relative humidity below the ambient humidity, compressed nitrogen was used to purge the spin coater. For relative humidity above the ambient humidity, compressed nitrogen was bubbled through deionized water en route to the spin coater. For both situations, the nitrogen flow rate was manually adjusted to achieve the desired relative humidity. $\mathrm{ZnO}$ films were cast by dispensing $250 \mu \mathrm{L}$ of solution onto the substrate and spinning at $7000 \mathrm{rpm}$ for $60 \mathrm{~s}$ with a $7000 \mathrm{rpm} / \mathrm{s}$ ramp. This produced films that were approximately $40 \mathrm{~nm}$ thick. For annealing a large expanded polystyrene box was used to cover a hot plate. It also had holes for the gas line and humidity meter and humidity was controlled in the same way as it was for spin coating. Selected samples were annealed in a nitrogen-filled glove box with less than 1 ppm water. All samples were annealed for 20 minutes on a hot plate set to $120^{\circ} \mathrm{C}$.

X-ray photoelectron spectroscopy (XPS) measurements were performed on a Kratos AXIS Nova XPS system. Following completion of annealing, the samples were sealed in vials in a $\mathrm{N}_{2}$-filled glove box. Ambient exposure during loading of the samples was less than 5 min. Photoelectrons were generated using monochromatic Al K $\alpha$ X-rays at $1486.6 \mathrm{eV}$. Pass energy was $10 \mathrm{eV}$. Base pressures were better than $1 \times 10^{-9}$ torr. Binding energy calibration was performed by shifting the advantitious C 1s peak to $284.6 \mathrm{eV}$. Analysis was performed using Vision Processing Software.

Spectroscopic ellipsometry measurements were made using a M2000 variable angle spectroscopic ellipsometer from the J.A. Woollam Co., Inc. The data was analyzed and modeled using the WVASE32 software (J.A. Woollam Co., Inc.). The Si wafers were measured prior to coating with zinc oxide for accurate measurement of the oxide layer thickness. The thickness of the oxide was determined using a model with the ntve_jaw.mat, sio2_jaw.mat, and si_jaw.mat material files found in the software. The thickness of the $\mathrm{ZnO}$ films was determined by fitting a Cauchy layer to the measured $\Psi$ and $\Delta$ values at energies below the band gap of $\mathrm{ZnO}$. Once the thickness was determined, it was fixed and a point-by-point fit was performed to estimate the refractive index and extinction coefficient at each point. The point-by-point fit does not enforce Kramers-Kronig consistency, so an oscillator model is necessary to ensure a physical model. Next, using the genosc.mat layer multiple oscillators were used to model the complex dielectric function of $\mathrm{ZnO}$ generated from the saved optical constants. This model incorporated a Tauc-Lorentz oscillator and three Gaussian oscilla- tors that were fit to the data. Additionally, an energy offset term and a pole at $11 \mathrm{eV}$ were included as fit parameters to better fit the real part of the dielectric function. The energy offset and pole terms are used to account for contributions from oscillators that are outside of the measured wavelength range. Finally, the oscillator model was fit to the measured $\Psi$ and $\Delta$ data.

Kelvin Probe measurements were made using an Ambient Kelvin Probe from KP Technologies, Inc. The tip was enclosed in a Faraday box, which was purged with $\mathrm{N}_{2}$. The $\mathrm{ZnO}$ films were prepared as described above. Reference measurements were made on samples of aluminum with a native oxide and gold, to ensure proper function of the system. For measurement of the $\mathrm{ZnO}$ films the samples were continuously measured under UV illumination. Due to the transient nature of $\mathrm{ZnO}$ work function the measurement was allowed to stabilize for at least $30 \mathrm{~min}$ before a value was recorded. The reported values are the average of at least 26 measured values.

X-ray diffraction (XRD) measurements were performed on a Rigaku D-max system, with $\mathrm{Cu} \mathrm{K} \alpha$ radiation, $\lambda=1.5418 \AA$. $\mathrm{ZnO}$ films were measured on quartz substrates.

Devices were fabricated on patterned ITO substrates. The $\mathrm{ZnO}$ films were coated as described above. For the P3HT:ICBA bulk heterojunction, P3HT (BASF P200) and ICBA (Plexcore OS 2500) with an 1:1 mass ratio were codisolved in 1,2-dichlorobenzene. The total solids concentration was $50 \mathrm{mg} / \mathrm{mL}$. The solution was stirred on a hot plate at $60{ }^{\circ} \mathrm{C}$ overnight. The solution was cooled for $10 \mathrm{~min}$ on the floor of the glove box before use. The bulk heterojunction was cast by dispensing $60 \mu \mathrm{L}$ of solution on the substrate and spreading it with the pipet tip, followed by spinning at 600 $\mathrm{rpm}$ for $60 \mathrm{~s}$ with a $300 \mathrm{rpm} / \mathrm{s}$ ramp. The still wet substrate was then transferred to a petri dish and covered and allowed to slowly dry for 2 hours. Following drying, the samples were annealed for 5 minutes on a hot plate set to $150{ }^{\circ} \mathrm{C}$. Devices were also fabricated with poly(\{4,8-bis[(2-ethylhexyl)oxy]benzo[1,2-b:4,5 -b']dithiophene-2,6-diyl $\}$ 33-fluoro-2-[(2-ethylhexyl) carbonyl]thieno[3,4-b]thiophenediyl $\}):[6,6]-$ phenyl-C 71 -butyric acid methyl ester (PTB7:PC 71 BM) BHJs. PTB7 (1-Material) and $\mathrm{PC}_{71} \mathrm{BM}$ (Nano-C) with a mass ratio of $1: 1.5$ were codisolved in chlorobenzene with $1,8-$ diiodooctane ( $97: 3$ by volume) at a total solids concentration of $25 \mathrm{mg} / \mathrm{mL}$. This solution was stirred and heated at $60{ }^{\circ} \mathrm{C}$ for 20 hours. The solution was spin coated at $1400 \mathrm{rpm}$ for $40 \mathrm{~s}$. Devices were dried for 30 min in covered petri dishes. For all OPV devices, the electrodes were deposited by thermal evaporation. The chamber was pumped down to a base pressure of $8 \times$ $10^{-8}$ torr. $8 \mathrm{~nm}$ of $\mathrm{MoO}_{3}$ was thermally evaporated at a rate of $0.2 \AA / s$ through a shadow mask. Then, without breaking vacuum, $100 \mathrm{~nm}$ of $\mathrm{Ag}$ (99.99\%) was evaporated at $0.5 \AA / \mathrm{s}$ for the first $10 \mathrm{~nm}$ and then 
Table 1: Calculated values of the ratio of stoichiometric $\left(\mathrm{O}_{\mathrm{i}}\right)$ to nonstoichiometric oxygen $\left(\mathrm{O}_{\mathrm{ii}}\right)$ and $\mathrm{Zn}$ to $\mathrm{O}$ from $\mathrm{x}$-ray photoelectron spectroscopy measurements. These data show that as humidity during formation increases so does the amount of stoichiometric oxygen and $\mathrm{Zn}$ content.

\begin{tabular}{ccccc}
\hline $\begin{array}{c}\text { Spin Hum. } \\
(\% \mathrm{RH})\end{array}$ & $\begin{array}{c}\text { Annealing Hum. } \\
(\% \mathrm{RH})\end{array}$ & $\mathrm{O}_{\mathrm{i}} / \mathrm{O}_{\mathrm{ii}}$ & $\begin{array}{c}\mathrm{Zn} \\
(\mathrm{at} \%)\end{array}$ & $\begin{array}{c}\mathrm{O} \\
(\mathrm{at} \%)\end{array}$ \\
\hline 13 & 0 & 0.76 & 48.15 & 51.15 \\
45 & 0 & 0.95 & 48.74 & 51.26 \\
45 & 45 & 1.08 & 49.05 & 50.95 \\
75 & 75 & 1.16 & 50.45 & 49.55 \\
\hline
\end{tabular}

increased to $2.0 \AA / \mathrm{s}$. The devices were measured in a glove box with a Newport $3 \mathrm{~A}$ solar simulator. The intensity of the lamp was adjusted to using a KG5filtered Si reference cell, which has a mismatch of less than $1 \%$ with P3HT:ICBA. The samples were illuminated through an aperture with an area of $0.061 \mathrm{~cm}^{2}$. Current-voltage sweeps were measured with a Keithley 2420 digital multimeter. Device performance metrics were calculated using Igor Pro (Wavemetrics). Statistics were calculated from between 6 and 12 individual cells. Cells with anomalous performance due to defects in films were removed from calculations.

\section{Results and Discussion}

Atomic force microscopy (AFM) and contact angle measurements (Supporting Information Table S1) were used to determine if the humidity impacted the surface of the $\mathrm{ZnO}$ films, since a previous report of $\mathrm{ZnO}$ films from a zinc acetate sol-gel solution showed that the surface roughness of $\mathrm{ZnO}$ had an effect on OPV device performance.[19] Here, both measurements showed only small differences between the surfaces of the films (Table S1). The $\mathrm{ZnO}$ films were also measured using X-ray diffraction (XRD), which showed no measurable difference between the samples (Fig. S1). Also, the XRD data do not show any evidence of crystallinity in these films (no crystalline peaks), which is likely due to the low annealing temperature. Together, the AFM and XRD indicate the different formation conditions result in films with similar structure.

\subsection{X-ray Photoelectron Spectroscopy}

In order to quantify the chemical composition of the surfaces of the $\mathrm{ZnO}$ films, $\mathrm{x}$-ray photoelectron spectroscopy (XPS) was used to measure the ratios of stoichiometric oxygen to non-stoichiometric oxygen, and zinc to oxygen. Fig. 1 shows the normalized $\mathrm{O} 1 \mathrm{~s}$ spectra for the films coated and annealed under different RH conditions. The spectra all display two peaks: the $\mathrm{O}_{\mathrm{i}}$ peak at $530.0 \mathrm{eV}$ (full width at half maximum (FWHM) $1.17 \mathrm{eV}$ ) corresponds to stoichiometric oxygen $(\mathrm{Zn}-\mathrm{O})$ within the lattice and the $\mathrm{O}_{\text {ii }}$ peak at 531.5 $\mathrm{eV}$ (FWHM $1.61 \mathrm{eV}$ ) corresponds to non-stoichiometric

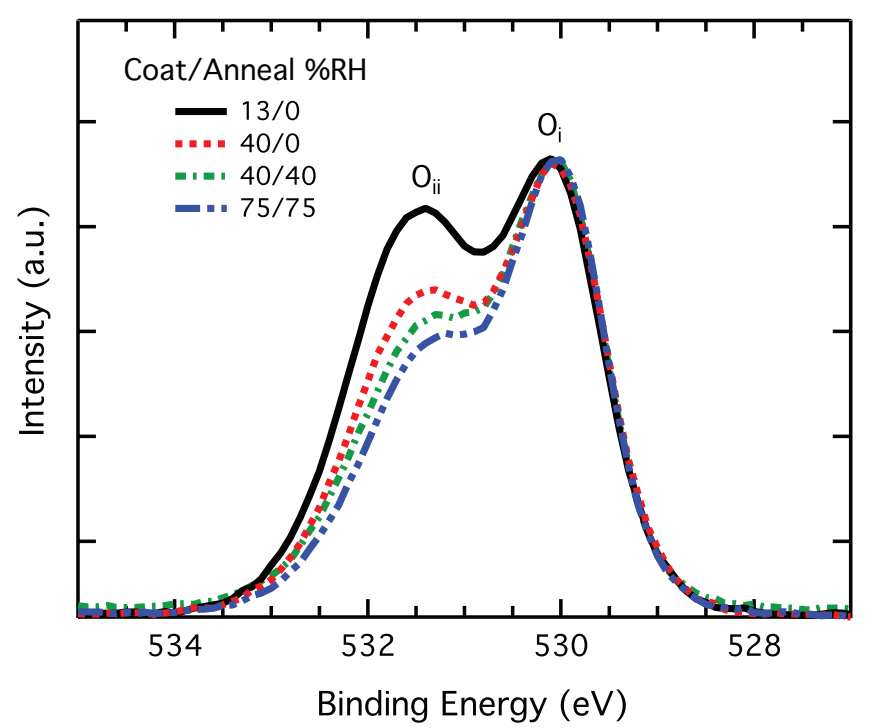

Figure 1: O 1s spectra measured by $\mathrm{x}$-ray photoelectron spectroscopy of $\mathrm{ZnO}$ films formed under different relative humidity conditions (Legend: \% RH coating/\% RH annealing). The stoichiometric $\left(\mathrm{O}_{\mathrm{i}}\right)$ and non-stoichiometric $\left(\mathrm{O}_{\mathrm{ii}}\right)$ oxygen peaks are labeled for comparison of the ratio of stoichiometric to non-stoichiometric oxygen in the $\mathrm{ZnO}$ films. These spectra show that as $\mathrm{RH}$ is increased during formation the film becomes more stoichiometric.

oxygen ( $\mathrm{Zn}-\mathrm{O}-\mathrm{H})$.[20] It is clearly seen that as humidity increases the intensity of the $\mathrm{O}_{\mathrm{ii}}$ peak decreases relative to the $\mathrm{O}_{\mathrm{i}}$ peak, which indicates an increase in stoichiometry of the oxide. The ratio of stoichiometric to non-stoichiometric oxide can be calculated by comparing the areas of two Gauss/Lorentz (70/30 ratio) oscillators fit to the peaks. These ratios are summarized in Table 1 and $\mathrm{O} 1 \mathrm{~s}$ spectra with peaks and fits are shown in Fig. S2. The atomic percentages of $\mathrm{Zn}$ and $\mathrm{O}$ in the films can also be found Table 1 . These percentages show that as \% RH is increased during film formation the $\mathrm{Zn} / \mathrm{O}$ ratio increases.

These results give insight to where in the formation process the hydrolysis and elimination reactions occur. Given that films coated in a humid environment and annealed in $0 \% \mathrm{RH}$ form $\mathrm{ZnO}$ films (with varying degrees of stoichiometry), it can be concluded that, to a large extent, hydrolysis occurs during coating. This is not surprising given that the hydrolysis of DEZn is highly exothermic. Comparing the two films spin coated at $40 \% \mathrm{RH}$ it is found that the oxide is more stoichiometric and the $\mathrm{Zn} / \mathrm{O}$ ratio is higher for the film annealed at $40 \% \mathrm{RH}$ than at $0 \% \mathrm{RH}$. This suggests that hydrolysis also occurs during annealing. With water present, any DEZn that was not reacted during coating can be converted to $\mathrm{Zn}\left(\mathrm{CH}_{2} \mathrm{CH}_{3}\right) \mathrm{OH}$ and then to $\mathrm{ZnO}$. This result supports the hypothesis of MacLeod et al. that the formation of $\mathrm{ZnO}$ from DEZn is kinetically limited.[11] Annealing in a more humid environment allows more of the trapped species to be fully reacted. 
Table 2: Kelvin probe measurements of the contact potential difference (CPD) relative to a gold alloy tip of $\mathrm{ZnO}$ films formed under different humidity conditions during spin coating and annealing. Values are reported with one standard deviation. The estimated work function of $\mathrm{ZnO}$ films $(\phi)$ were calculated relative to a native aluminum oxide sample. The results show that as humidity is increased, so is $\phi$

\begin{tabular}{ccc}
\hline $\begin{array}{c}\text { Spin Hum. } \\
(\% \mathrm{RH})\end{array}$ & $\begin{array}{c}\text { Annealing Hum. } \\
(\% \mathrm{RH})\end{array}$ & $\begin{array}{c}\text { CPD } \\
(\mathrm{mV})\end{array}$ \\
\hline 12 & 0 & $-678 \pm 4$ \\
12 & 11 & $-594 \pm 2$ \\
48 & 0 & $-584 \pm 2$ \\
48 & 54 & $-523 \pm 2$ \\
75 & 75 & $-495 \pm 2$ \\
\hline
\end{tabular}

Elimination is endothermic and occurs during annealing. However, it is unclear how the elimination reaction effects the stoichiometry of the these films since it cannot be isolated from hydrolysis, which appears to be occurring during coating and annealing.

\subsection{Kelvin Probe}

In light of the XPS results that show differences in the chemical composition of the surfaces of $\mathrm{ZnO}$ films formed under different $\mathrm{RH}$, it is important to quantify how this effects the electronic properties of these films. The work function $(\phi)$ is the most relevant measurement given that it is a surface electrical property. The contact potential difference $\left(\mathrm{CPD}=\phi_{\text {tip }}-\phi_{\text {sample }}\right)$ of the $\mathrm{ZnO}$ films was measured after UV light soaking in nitrogen. Previous results have shown that UV light soaking results in a slight decrease in work function due to desorption of chemisorbed oxygen.[21] Light soaking of the $\mathrm{ZnO}$ mimics conditions that are most relevant to OPV devices given the correlation between UV effect on charge extraction and current-voltage characteristics.[22] Five processing conditions were measured and the results are displayed in Table 2. The data show that decreasing humidity during $\mathrm{ZnO}$ formation leads to a more negative CPD, which translates to a smaller $\phi$ (closer to vacuum). The changes in $\phi$ are likely due to changes in composition and stoichiometry of the surface. These observed differences in $\phi$ have implications for OPV device efficiency. A shift in $\phi$ is indicative of a shift in the vacuum level relative to the energy levels of $\mathrm{ZnO}$. This shift should result in improved energy level alignment between $\mathrm{ZnO}$ and the fullerene and a larger built-in field.

\subsection{Spectroscopic Ellipsometry}

Spectroscopic ellipsometry is a powerful technique to characterize the optoelectronic properties of thin films Using a collection of oscillators the dielectric function of thin films can be modeled. For solution-deposited $\mathrm{ZnO}$ thin films, the dielectric function from 300 - 1700 $\mathrm{nm}$ has been successfully modeled using Gaussian oscillators and a Tauc-Lorentz (TL) oscillator.[23] The

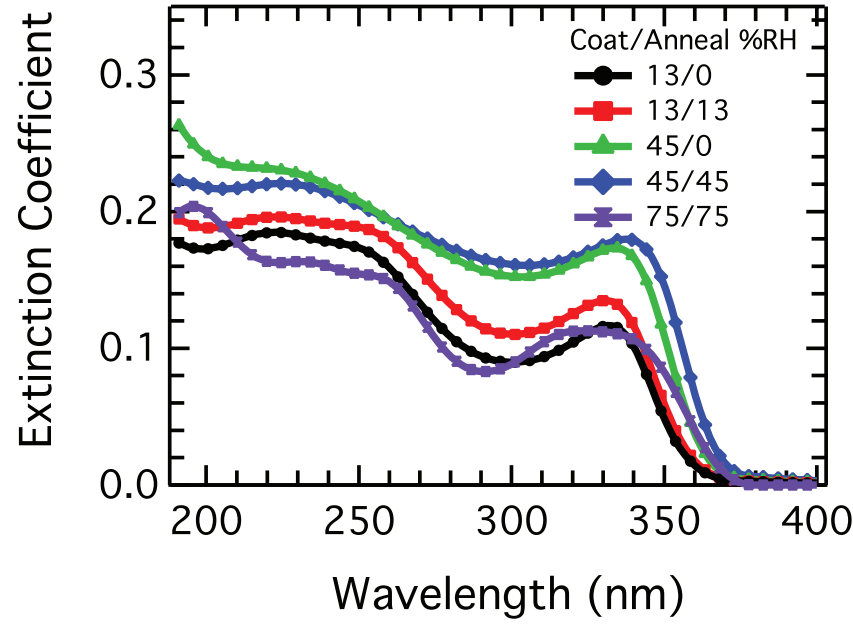

Figure 2: Extinction coefficient of $\mathrm{ZnO}$ films formed under different humidity conditions (Legend: \% RH coating/\% RH annealing) generated from oscillator model fits to spectroscopic ellipsometry data. Reducing humidity during film formation results in a larger band gap and and a decrease in the extinction coefficient near the onset of absorption.

TL oscillator is a Lorentz oscillator multiplied by the Tauc joint density of states function and was developed to better model the band-edge of amorphous semiconductors and insulators.[24] The imaginary part of the TL oscillator is defined as

$$
\varepsilon_{2}^{T L}=\left\{\begin{array}{cl}
\frac{A E_{c} B\left(E-E_{g}\right)^{2}}{\left(E^{2}-E_{g}^{2}\right)^{2}+B^{2} E^{2}} \cdot \frac{1}{E} & E>E_{g} \\
0 & E \leq E_{g}
\end{array}\right.
$$

where $A$ is oscillator amplitude, $B$ is the broadening, $E_{c}$ is the peak transition energy, and $E_{g}$ is the optical band gap energy. When characterizing $\mathrm{ZnO}$ films, the TL oscillator model makes it possible to directly fit $E_{g}$. The Gaussian oscillators are used to model the dielectric function at energies above the band edge. Five $\mathrm{ZnO}$ films formed under different coating and annealing humidity conditions were prepared on $\mathrm{Si}$ wafers with $100 \mathrm{~nm}$ of thermal oxide: 13/0, 13/13/45/0, 45/45, and $75 / 75 \% \mathrm{RH}$. The oscillator parameters obtained from the best fits are reported in Table S2. Two other fit parameters $\varepsilon_{1}(\infty)$ and an unbroadened pole at $11 \mathrm{eV}$ are included for the Kramers-Kronig integration to determine the real part of the dielectric function. Figures showing $\varepsilon_{2}$ for the films with the contributions of each oscillator are shown in Fig. S3.

The extinction coefficients of the films are shown in Fig. 2. The parameters of the Tauc-Lorentz oscillators are reported in Table 3. It is clear from the parameters and extinction coefficient plot that as relative humidity increases during formation, either coating, annealing, or both, $E_{g}$ decreases. This is consistent with results from RF sputtered and atomic layer deposited $\mathrm{ZnO}$ that show $E_{g}$ decreases as the $\mathrm{Zn} / \mathrm{O}$ ratio increases.[25, 26] A film was also measured after spin 
Table 3: Best-fit parameters for the Tauc-Lorentz oscillators used to fit dielectric function for $\mathrm{ZnO}$ films measured by ellipsometry. As the humidity exposure is increased there is an observable decrease in the band gap energy. Values are reported with $90 \%$ confidence intervals.

\begin{tabular}{cccccc}
\hline $\begin{array}{c}\text { Coating } \\
\text { Hum. }(\% \mathrm{RH})\end{array}$ & $\begin{array}{c}\text { Annealing } \\
\text { Hum. }(\% \mathrm{RH})\end{array}$ & $\begin{array}{c}A \\
(\mathrm{eV})\end{array}$ & $\begin{array}{c}E_{c} \\
(\mathrm{eV})\end{array}$ & $\begin{array}{c}B \\
(\mathrm{eV})\end{array}$ & $\begin{array}{c}E_{g} \\
(\mathrm{eV})\end{array}$ \\
\hline 13 & 0 & $16.1 \pm 0.15$ & $3.61 \pm 0.005$ & $0.390 \pm 0.008$ & $3.32 \pm 0.004$ \\
13 & 13 & $19.2 \pm 0.11$ & $3.60 \pm 0.002$ & $0.42 \pm 0.006$ & $3.31 \pm 0.002$ \\
45 & 0 & $31.7 \pm 0.07$ & $3.54 \pm 0.008$ & $0.40 \pm 0.002$ & $3.31 \pm 0.001$ \\
45 & 45 & $36.3 \pm 0.06$ & $3.49 \pm 0.001$ & $0.38 \pm 0.001$ & $3.28 \pm 0.001$ \\
75 & 75 & $23.8 \pm 0.07$ & $3.46 \pm 0.001$ & $0.50 \pm 0.002$ & $3.27 \pm 0.001$ \\
\hline
\end{tabular}

coating at $13 \% \mathrm{RH}$ and without annealing, so it should not be converted to $\mathrm{ZnO}$. Measurement and analysis of the optical properties of the film show that it does not start to absorb until above $5 \mathrm{eV}$ (Fig. S4), well above the band gap of $\mathrm{ZnO}$.

Another trend observed is an increase in extinction coefficient with increasing humidity up to $45 \% \mathrm{RH}$. This can be seen in Fig. 2 and by comparison of the TL oscillator amplitude $(A)$ in Table 3 . The $75 / 75 \% \mathrm{RH}$ sample does not fit this trend. However, there were some difference between $75 / 75 \% \mathrm{RH}$ sample and the other $\mathrm{ZnO}$ films. First, is that the $75 / 75 \% \mathrm{RH}$ films were about $10 \mathrm{~nm}$ thicker than the films cast at lower humidities. This was observed in multiple film preparations and was independent of the order in which the films were prepared. The second difference is that the $75 / 75 \%$ RH sample required 4 Gaussian oscillators to accurately model the dielectric function where as the other $\mathrm{ZnO}$ films only required 3 Gaussian oscillators. This suggests there is physical change in the $\mathrm{ZnO}$ films formed at high humidity that is impacting the optoelectronic properties of the film. It is not possible to definitively say what this change is (aside from film thickness) since the Gaussian oscillators have not been ascribed to specific electronic transitions.[23]

\subsection{Organic Photovoltaic Devices}

To test the effects of $\mathrm{ZnO}$ properties on OPV efficiency, inverted devices with a P3HT:ICBA BHJ were fabricated with $\mathrm{ZnO}$ ECLs that were formed under different humidity conditions. For these devices the humidities during spin coating were 13,45 , and $75 \% \mathrm{RH}$ and for annealing the humidities were $0,13,45$, and $70 \% \mathrm{RH}$. Spin coating at $0 \% \mathrm{RH}$ was not tested because a water source in necessary for the hydrolysis reaction that occurs during the drying of the spin coated solution. As such, spin coating in a $0 \% \mathrm{RH}$ environment will not produce useful films. The current density/voltage $(J V)$ curves for devices with the ZnO ECLs spin coated and annealed at different \% RH values are shown in Fig. 3(a) and their performance metrics are reported in Table 4. The most efficient devices were fabricated with $\mathrm{ZnO}$ coating at $13 \% \mathrm{RH}$ and annealing at $0 \% \mathrm{RH}$. These conditions produced an average $V_{o c}$, $J_{s c}, F F$, and PCE of $821 \mathrm{mV}, 9.25 \mathrm{~mA} / \mathrm{cm}^{2}, 68.8 \%$, and $5.23 \%$. The least efficient devices had ZnO ECLs coated at $75 \% \mathrm{RH}$ and annealed at $75 \% \mathrm{RH}$. These devices had an average $V_{o c}, J_{s c}, F F$, and $P C E$ of $764 \mathrm{mV}$, $9.57 \mathrm{~mA} / \mathrm{cm}^{2}, 58.1 \%$, and $4.25 \%$.

To more clearly illustrate the trends $V_{o c}, F F$, and $P C E$ are plotted as a function of annealing humidity for all of the spin coating and annealing humidities (Fig. 4) . The average device metrics for all measured samples are also tabulated in Table S3. Humidity does not appear to affect $J_{s c}$. For a fixed coating humidity, decreasing the annealing humidity increases $V_{o c}$ and $F F$. The same trend is observed for decreasing coating humidity at a fixed annealing humidity. These data clearly show that reducing humidity during spin coating and annealing increases $V_{o c}$ and $F F$.

Since the P3HT:ICBA BHJs were thermally annealed to improve the morphology of the $\mathrm{BHJ}$, it is possible that the improvements in efficiency could be due to some unknown thermally-induced interactions between the $\mathrm{BHJ}$ and $\mathrm{ZnO}$ and not the intrinsic properties of the $\mathrm{ZnO}$. To test this possibility, devices were also fabricated with a PTB7: $\mathrm{PC}_{71} \mathrm{BM}$ BHJ, which achieves maximum efficiency without thermal annealing. Devices were fabricated with the $\mathrm{ZnO}$ coated and annealed at different humidities (Fig. 3 and Table 4). These device data show that reducing humidity either during coating or annealing increases $V_{o c}$, consistent with what is seen in the P3HT:ICBA devices. Unlike the P3HT:ICBA devices, there does not appear to be a trend in $F F$ with humidity.

Taken in aggregate with the Kelvin probe data, the device data suggests the observed improvements in $V_{o c}$ follows a vacuum shift as evidenced by the change in $\phi$. This same relationship between $V_{o c}$ and $\phi$ has previously been reported where $\phi$ of $\mathrm{ZnO}$ has been manipulated using organic additives for nanoparticle $\mathrm{ZnO}$ ECLs or phosphonic acid SAMs for $\mathrm{ZnO}$ from DEZn.[27, 28, 22] Similar to what has been previously observed, the change in $V_{o c}$ is smaller than the change in $\phi$, which has been attributed to Fermi-level pinning. [28, 29, 30, 31, 32] The shift in $\phi$ of $\mathrm{ZnO}$ would increase the built-in field within the device, therefore increasing $V_{o c}$. ZnO formation humidity did not affect the series resistance of the devices, which indicates that potential changes in $\mathrm{ZnO}$ conductivity due to changes in stoichiometry are not responsible for changes in $V_{o c}$ and $F F$. 
Table 4: Average device performance metrics for P3HT:ICBA and PTB7:PC 71 BM BHJ devices with ZnO layers that were spin coated and annealed under different humidity conditions. These results show that decreasing humidity during coating and annealing increases $V_{o c}$, and for P3HT:ICBA, FF.

\begin{tabular}{cccccc}
\hline $\begin{array}{c}\text { Spin Hum. } \\
(\% \mathrm{RH})\end{array}$ & $\begin{array}{c}\text { Annealing Hum. } \\
(\% \mathrm{RH})\end{array}$ & $\begin{array}{c}V_{o c} \\
(\mathrm{mV})\end{array}$ & $\begin{array}{c}J_{s c} \\
\left(\mathrm{~mA} / \mathrm{cm}^{2}\right)\end{array}$ & $\begin{array}{c}F F \\
(\%)\end{array}$ & $\begin{array}{c}P C E \\
(\%)\end{array}$ \\
\hline P3HT:ICBA & & & & & \\
13 & 0 & $821 \pm 7$ & $9.25 \pm 0.2$ & $68.8 \pm 0.7$ & $5.23 \pm 0.2$ \\
13 & 13 & $811 \pm 6$ & $9.63 \pm 0.1$ & $65.4 \pm 1.9$ & $5.11 \pm 0.2$ \\
45 & 0 & $796 \pm 8$ & $9.68 \pm 0.3$ & $65.4 \pm 3.7$ & $5.05 \pm 0.5$ \\
45 & 45 & $789 \pm 5$ & $9.56 \pm 0.3$ & $63.1 \pm 1.7$ & $4.76 \pm 0.2$ \\
75 & 75 & $764 \pm 11$ & $9.57 \pm 0.2$ & $58.1 \pm 2.7$ & $4.25 \pm 0.3$
\end{tabular}

\begin{tabular}{cccccc} 
PTB7:PC & BM & & & & \\
13 & 0 & $752 \pm 4$ & $13.6 \pm 0.2$ & $68.3 \pm 0.9$ & $7.01 \pm 0.1$ \\
45 & 0 & $733 \pm 5$ & $13.8 \pm 0.5$ & $70.1 \pm 0.3$ & $7.08 \pm 0.3$ \\
45 & 45 & $715 \pm 6$ & $13.5 \pm 0.3$ & $67.4 \pm 0.4$ & $6.50 \pm 0.2$ \\
\hline
\end{tabular}

(a)

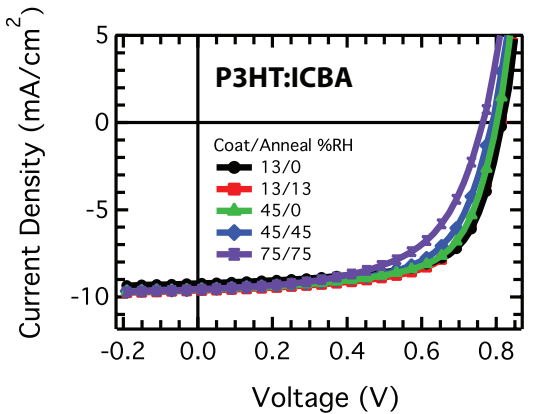

(b)

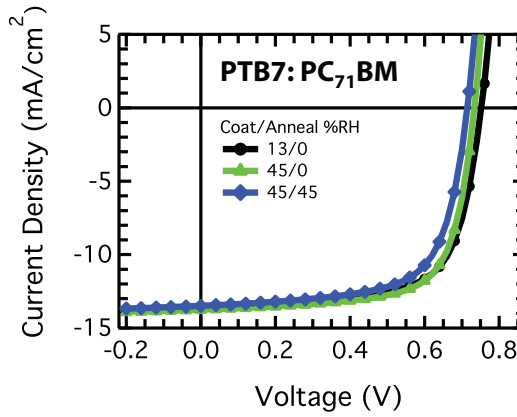

(c)

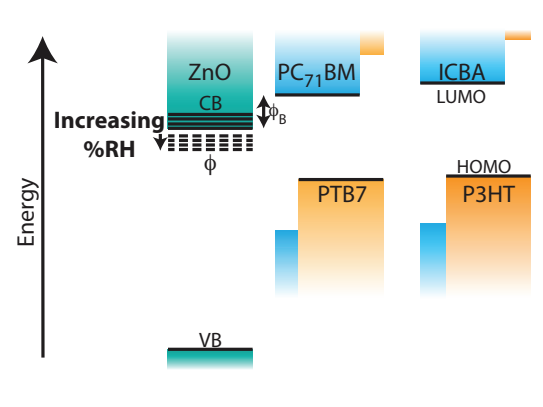

Figure 3: Average current density-voltage $(J V)$ curves for (a) P3HT:ICBA and (b) PTB7:PC ${ }_{71}$ BM BHJ OPV devices with ZnO ECLs that were spin coated were spin coated and annealed under different humidity conditions (spin/anneal). The $J-V$ curves show that reducing the humidity during $\mathrm{ZnO}$ formation leads to improvements in $V_{o c}$, and FF for P3HT:ICBA . (c) Energy level diagram for ZnO, P3HT, ICBA, PTB7, and $\mathrm{PC}_{71} \mathrm{BM}$. The energy difference between the fullerene LUMO and ZnO CB is illustrated as $\phi_{B}$. 
The increase in $V_{o c}$ may also be attributed to a changes in energy barrier between the fullerene LUMO and the $\mathrm{ZnO}$ conduction band (CB), as illustrated by $\phi_{B}$ in Fig. 3c. These offset between these transport levels is significant because electrons are injected from the fullerene LUMO to the $\mathrm{ZnO} \mathrm{CB}$. An offset between these levels is will cause the electron to lose voltage when it is injected to the $\mathrm{ZnO}$. The change in $\phi$ should result in a shift in the alignment between the fullerene LUMO and the $\mathrm{ZnO} \mathrm{CB}$. As $\phi$ moves towards the vacuum it will push CB closer to the fullerene LUMO. This decreases the energetic loss of an electron injected to the $\mathrm{ZnO} \mathrm{CB}$ from the fullerene LUMO. Decreasing this loss, as humidity is decreased, will increase $V_{o c}$.

Differences between the LUMO energies of the fullerenes could also explain the different trends in $\mathrm{FF}$ between the two BHJs. PC ${ }_{71}$ BM's LUMO is further from the vacuum level than ICBA's LUMO, making it is closer to the $\mathrm{ZnO} \mathrm{CB}$, as illustrated in Fig. 3c.[33, $34,35]$ Because $\phi_{B}$ is smaller for $\mathrm{PC}_{71} \mathrm{BM}$ than ICBA, thus making it smaller and moving ZnO's $\mathrm{CB}$ closer to $\mathrm{PC}_{71}$ BM's LUMO may have a negligible effect of $F F$. But with ICBA, $\phi_{B}$ is larger, so moving CB closer to the LUMO of ICBA appears to have a larger effect on FF.

Our OPV device results differ with the results of Bao Foong, et al.[17] They report that the most efficient P3HT:PC ${ }_{61} \mathrm{BM}$ devices are obtained with the $\mathrm{ZnO}$ layer coated and annealed at $75 \% \mathrm{RH}$. However, in their study, annealing conditions were variable (110 - $350{ }^{\circ} \mathrm{C}$ ) when comparing the $\mathrm{ZnO}$ formation at different humidities, so the changes in device efficiency they observe may be due to differences in annealing temperature not humidity. It should also be noted that when comparing $\mathrm{ZnO}$ formation conditions, their devices utilized un-annealed $\mathrm{P} 3 \mathrm{HT}: \mathrm{PC}_{61} \mathrm{BM} \mathrm{BHJ}$, which have poor exciton separation. Their devices had measured $F F$ below $40 \%$ suggesting their results may be confounded by low free-charge generation in the BHJ. Only PCE values at one \% RH are reported for OPV devices with annealed (optimized) P3HT:PC ${ }_{61} \mathrm{BM}$, so it is not possible to directly compare their results to ours. The results presented here use two optimized BHJs (one annealed and one unannealed) and a consistent $\mathrm{ZnO}$ annealing temperature. Also, BHJs presented here have been optimized with and without thermal annealing thereby providing results free of deficiencies in exciton separation or charge transport in the BHJ. Our results show reducing humidity during $\mathrm{ZnO}$ ECL film formation from stabilized DEZn results in the most efficient OPV devices.

\section{Conclusions}

The effects of humidity during the formation of $\mathrm{ZnO}$ from a diethylzinc precursor solution were quantified using XPS, Kelvin probe, and spectroscopic el-

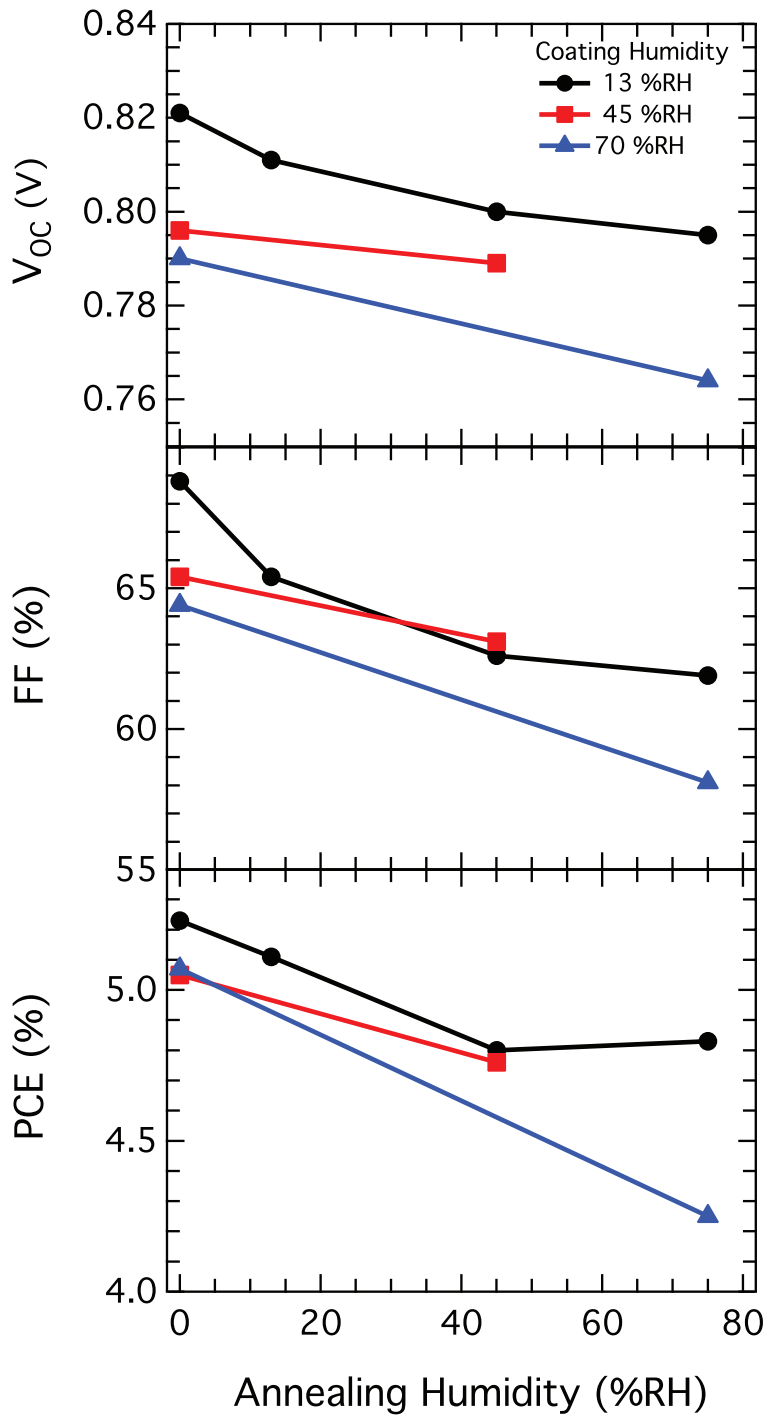

Figure 4: Plots of $V_{o c}, F F$, and $P C E$ as a function of annealing humidity during $\mathrm{ZnO}$ ELC formation. The spin coating humidity is indicated by the color of the makers and lines: $13 \% \mathrm{RH}$ (black circles), $45 \% \mathrm{RH}$ (red squares), $70 \% \mathrm{RH}$ (blue triangles). Regardless of the spin coating humidity, these data show that decreasing the humidity during annealing has a positive effect on these three parameters. $\mathrm{J}_{S C}$ is not shown because it is not affected by the $\mathrm{ZnO}$ formation conditions. 
lipsometry and OPV device studies. Decreasing humidity during coating and annealing is shown to decrease the oxide stoichiometry and $\mathrm{Zn} / \mathrm{O}$ ratio. Kelvin probe measurements show that the films formed under lower humidity exhibit lower work function. When incorporated into OPV devices, ZnO ECLs formed in reduced humidity result in higher $V_{o c}$ and, in most cases, FF. The improvements in $V_{o c}$ follow the observed shifts in $\phi$ measured by Kelvin probe. These improvement in $V_{o c}$ are attributed to: 1) improved alignment between the energy levels of the fullerene and $\mathrm{ZnO}$, and 2) increased built-in field in the devices, both of which are derived from decreasing $\phi$. These results highlight the need for a controlled environment during $\mathrm{ZnO}$ formation. It also indicates that obtaining the highest quality (stoichiometric) $\mathrm{ZnO}$ does not necessarily result in the most efficient OPV devices.

\section{Acknowledgements}

Funding for this work provided was by SolarWindow Technologies, Inc. This work was supported by the U.S. Department of Energy under Contract No. DEAC36-08GO28308 with the National Renewable Energy Laboratory. S.A.M. would like to acknowledge Dr. Bradley A. MacLeod and Dr. Stefan Oosterhout for thoughtful discussions related to this work. S.R.H. would like to acknowledge Dr. Martin Drees for helpful discussions related to this work.

[1] C. J. Mulligan, C. Bilen, X. Zhou, W. J. Belcher, P. C. Dastoor, Levelised cost of electricity for organic photovoltaics, Sol. Energ. Mat. Sol. Cells 133 (2015) 26-31.

[2] M. A. Green, K. Emery, Y. Hishikawa, W. Warta, E. D. Dunlop, Solar cell efficiency tables (version 44), Prog. Photovolt: Res. Appl. 22 (7) (2014) 701-710.

[3] D. Angmo, P. M. Sommeling, R. Gupta, M. Hosel, S. A. Gevorgyan, J. M. Kroon, G. U. Kulkarni, F. C. Krebs, Outdoor Operational Stability of Indium-Free Flexible Polymer Solar Modules Over 1 Year Studied in India, Holland, and Denmark, Adv. Energy Mater. 16 (8) (2014) 976-987.

[4] S. K. Hau, H.-L. Yip, H. Ma, A. K. Y. Jen, High performance ambient processed inverted polymer solar cells through interfacial modification with a fullerene self-assembled monolayer, Appl. Phys. Lett. 93 (23) (2008) 233304.

[5] M. T. Lloyd, C. H. Peters, A. Garcia, I. V. Kauvar, J. J. Berry, M. O. Reese, M. D. McGehee, D. S. Ginley, D. C. Olson, Influence of the hole-transport layer on the initial behavior and lifetime of inverted organic photovoltaics, Sol. Energ. Mat. Sol. Cells 95 (5) (2011) 1382-1388.

[6] T. Shirakawa, T. Umeda, Y. Hashimoto, A. Fujii, K. Yoshino, Effect of $\mathrm{ZnO}$ layer on characteristics of conducting polymer/C 60photovoltaic cell, J. Phys. D: Appl. Phys. 37 (6) (2004) 847850.

[7] J. Y. Kim, S. H. Kim, H. H. Lee, K. Lee, W. Ma, X. Gong, A. J. Heeger, New Architecture for High-Efficiency Polymer Photovoltaic Cells Using Solution-Based Titanium Oxide as an Optical Spacer, Adv. Mater. 18 (5) (2006) 572-576.

[8] S. K. Hau, H.-L. Yip, N. S. Baek, J. Zou, K. O’Malley, A. K. Y. Jen, Air-stable inverted flexible polymer solar cells using zinc oxide nanoparticles as an electron selective layer, Appl. Phys. Lett. 92 (25) (2008) 253301.

[9] M. S. White, D. C. Olson, S. E. Shaheen, N. Kopidakis, D. S. Ginley, Inverted bulk-heterojunction organic photovoltaic de- vice using a solution-derived $\mathrm{ZnO}$ underlayer, Appl. Phys. Lett. 89 (14) (2006) 143517-143513.

[10] W. J. E. Beek, L. H. Slooff, M. M. Wienk, J. M. Kroon, R. A. J. Janssen, Hybrid Solar Cells Using a Zinc Oxide Precursor and a Conjugated Polymer, Adv. Funct. Mater. 15 (10) (2005) 1703-1707.

[11] B. A. MacLeod, B. Tremolet de Villers, P. Schulz, P. F. Ndione, H. Kim, A. J. Giordano, K. Zhu, S. R. Marder, S. Graham, J. J. Berry, A. Kahn, D. C. Olson, Stability of inverted organic solar cells with $\mathrm{ZnO}$ contact layers deposited from precursor solutions , Energy Environ. Sci. 8 (2015) 592-601.

[12] Y. Sun, J. H. Seo, C. J. Takacs, J. Seifter, A. J. Heeger, Inverted Polymer Solar Cells Integrated with a LowTemperatureAnnealed SolGelDerived ZnO Film as an Electron Transport Layer, Adv. Mater. 23 (14) (2011) 1679-1683.

[13] L. K. Jagadamma, M. Abdelsamie, A. El Labban, E. Aresu, G. O. N. Ndjawa, D. H. Anjum, D. Cha, P. M. Beaujuge, A. Amassian, Efficient inverted bulk-heterojunction solar cells from low-temperature processing of amorphous $\mathrm{ZnO}$ buffer layers , J. Mater. Chem. A 2 (33) (2014) 13321-13331.

[14] S. M. Smith, H. B. Schlegel, Molecular Orbital Studies of Zinc Oxide Chemical Vapor Deposition: Gas-Phase Hydrolysis of Diethyl Zinc, Elimination Reactions, and Formation of Dimers and Tetramers, Chem. Mater. 15 (1) (2003) 162-166.

[15] R. J. Herold, S. L. Aggarwal, V. Neff, Mechanisms of the reactions of diethylzinc with isopropanol and water, Canadian Journal of ... (1963) 1368-1380.

[16] W. J. E. Beek, Hybrid Polymer Solar Cells, Ph.D. thesis, Teschnische Universiteit Eindhoven (2005).

[17] T. R. Bao Foong, S. P. Singh, P. Sonar, Z.-E. Ooi, K. L. Chan, A. Dodabalapur, ZnO layers for opto-electronic applications from solution-based and low-temperature processing of an organometallic precursor, J. Mater. Chem. 22 (39) (2012) 20896.

[18] E. Guziewicz, M. Godlewski, L. Wachnicki, T. A. Krajewski, G. Luka, S. Gieraltowska, R. Jakiela, A. Stonert, W. Lisowski, M. Krawczyk, J. W. Sobczak, A. Jablonski, ALD grown zinc oxide with controllable electrical properties, Semicond. Sci. Technol. 27 (7) (2012) 074011.

[19] Z. Liang, Q. Zhang, O. Wiranwetchayan, J. Xi, Z. Yang, K. Park, C. Li, G. Cao, Effects of the Morphology of a ZnO Buffer Layer on the Photovoltaic Performance of Inverted Polymer Solar Cells, Adv. Funct. Mater. 22 (10) (2012) 21942201.

[20] P. J. Hotchkiss, M. Malicki, A. J. Giordano, N. R. Armstrong, S. R. Marder, Characterization of phosphonic acid binding to zinc oxide, J. Mater. Chem. 21 (9) (2011) 3107-3112.

[21] Q. Bao, X. Liu, Y. Xia, F. Gao, L.-D. Kauffmann, O. Margeat, J. Ackermann, M. Fahlman, Effects of ultraviolet soaking on surface electronic structures of solution processed $\mathrm{ZnO}$ nanoparticle films in polymer solar cells, J. Mater. Chem. A 2 (41) (2014) 17676-17682.

[22] S. R. Cowan, P. Schulz, A. J. Giordano, A. Garcia, B. A. MacLeod, S. R. Marder, A. Kahn, D. S. Ginley, E. L. Ratcliff, D. C. Olson, Chemically Controlled Reversible and Irreversible Extraction Barriers Via Stable Interface Modification of Zinc Oxide Electron Collection Layer in Polycarbazolebased Organic Solar Cells, Adv. Funct. Mater. 24 (29) (2014) $4671-4680$

[23] G. Lakhwani, R. F. H. Roijmans, A. J. Kronemeijer, J. Gilot, R. A. J. Janssen, S. C. J. Meskers, Probing Charge Carrier Density in a Layer of Photodoped ZnO Nanoparticles by Spectroscopic Ellipsometry, J. Phys. Chem. C 114 (35) (2010) 1480414810.

[24] G. E. Jellison, Jr, F. A. Modine, Parameterization of the optical functions of amorphous materials in the interband region, Appl. Phys. Lett. (1996) 371-373.

[25] A. Ismail, M. J. Abdullah, The structural and optical properties of $\mathrm{ZnO}$ thin films prepared at different RF sputtering power, J. King Saud Univ. Sci. 25 (2013) 209-215.

[26] A. A. Chaaya, R. Viter, M. Bechelany, Z. Alute, D. Erts, A. Za- 
lesskaya, K. Kovalevskis, V. Rouessac, V. Smyntyna, P. Miele, Evolution of microstructure and related optical properties of $\mathrm{ZnO}$ grown by atomic layer deposition, Beilstein J. Nanotechnol. 4 (1) (2013) 690-698.

[27] Y.-J. Lee, J. Wang, S. R. Cheng, J. W. P. Hsu, Solution Processed $\mathrm{ZnO}$ Hybrid Nanocomposite with Tailored Work Function for Improved Electron Transport Layer in Organic Photovoltaic Devices, ACS Appl. Mater. Interfaces 5 (18) (2013) 9128-9133.

[28] J. L. Braid, U. Koldemir, A. Sellinger, R. T. Collins, T. E. Furtak, D. C. Olson, Conjugated Phosphonic Acid Modified Zinc Oxide Electron Transport Layers for Improved Performance in Organic Solar Cells, ACS Appl. Mater. Interfaces 6 (21) (2014) 19229-19234.

[29] T. M. Brenner, G. Chen, E. P. Meinig, D. J. Baker, D. C. Olson, R. T. Collins, T. E. Furtak, Tuning zinc oxide/organic energy level alignment using mixed triethoxysilane monolayers, J. Mater. Chem. C 1 (37) (2013) 5935-5943.

[30] S. Braun, W. R. Salaneck, M. Fahlman, Energy-Level Alignment at Organic/Metal and Organic/Organic Interfaces, Adv. Mater. 21 (14-15) (2009) 1450-1472.

[31] V. D. Mihailetchi, P. W. M. Blom, J. C. Hummelen, M. T. Rispens, Cathode dependence of the open-circuit voltage of polymer:fullerene bulk heterojunction solar cells, J. Appl. Phys. 94 (10) (2003) 6849.

[32] M. T. Greiner, M. G. Helander, W.-M. Tang, Z.-B. Wang, J. Qiu, Z.-H. Lu, Universal energy-level alignment of molecules on metal oxides, Nat. Mater. 11 (1) (2012) 76-81.

[33] M. M. Wienk, J. M. Kroon, W. J. H. Verhees, J. Knol, J. C. Hummelen, P. A. van Hal, R. A. J. Janssen, Efficient Methano[70]fullerene/MDMO-PPV Bulk Heterojunction Photovoltaic Cells - Wienk - 2003 - Angewandte Chemie - Wiley Online Library, Angew. Chem. 115 (29) (2003) 3493-3497.

[34] Y. He, H.-Y. Chen, J. Hou, Y. Li, IndeneC 60Bisadduct: A New Acceptor for High-Performance Polymer Solar Cells, J. Am. Chem. Soc. 132 (4) (2010) 1377-1382.

[35] E. L. Ratcliff, B. Zacher, N. R. Armstrong, Selective Interlayers and Contacts in Organic Photovoltaic Cells, J. Phys. Chem. Lett. 2 (2011) 1337-1350. 


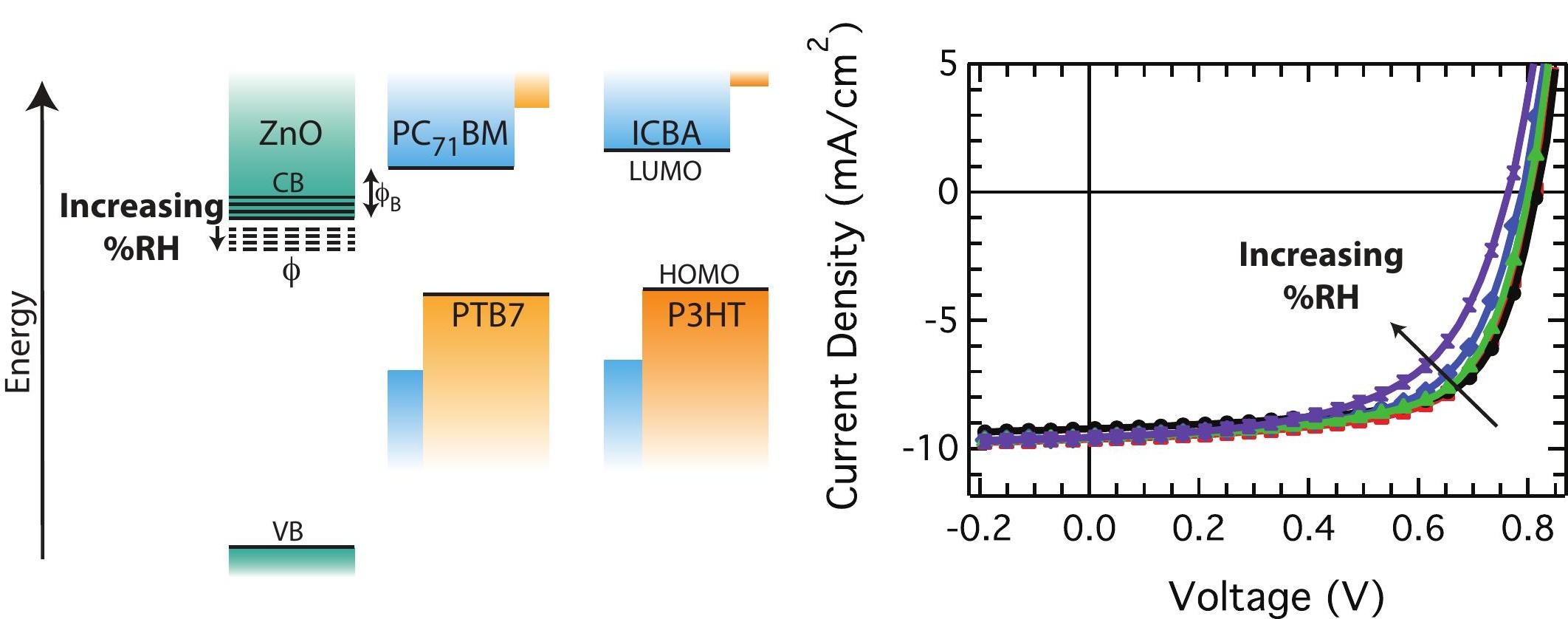

